\title{
Schedule-induced behavior in rats: Pellets versus powder
}

\author{
CHARLES H. M. BECK, THOMAS J. S. HUH, DAVE G. MUMBY, \\ and MARIAN E. FUNDYTUS \\ University of Alberta, Edmonton, Alberta, Canada
}

\begin{abstract}
Food-deprived rats develop polydipsia on an intermittent schedule (fixed time $60 \mathrm{sec}$ ) of food pellet delivery, but not on an identical schedule of food powder delivery. This result was demonstrated with separate groups receiving each type of food and was replicated using rats as their own controls. Powdered food not only prevented the development of polydipsia, but it abruptly terminated ongoing polydipsia in rats that were switched from the scheduled delivery of pellets to powder. Ethological analysis of the behavior showed that the rats receiving powder were not engaging excessively in some behavior other than drinking. After discounting several factors, we concluded that the amount of oral activity associated with feeding, which occurred immediately after food delivery, was reciprocally related to the level of drinking.
\end{abstract}

In a review of schedule-induced behavior in general, Roper (1981) noted that schedule-induced polydipsia may be a relatively rare phenomenon. This conjecture was based on the observation that few other adjunctive behaviors have been demonstrated to be persistent and excessive relative to massed-food and no-food control conditions. This being the case, Roper suggested that an explanation of schedule-induced polydipsia should focus on the interaction between feeding and drinking.

In preliminary testing, we measured schedule-induced polydipsia under a variety of conditions, one of these being to present dry powder prepared by grinding food pellets. When the powder was delivered on a fixed time (FT) 60-sec schedule, hungry rats failed to develop polydipsia. Moreover, rats that were already polydipsic, as a consequence of pellet training, abruptly lost their polydipsia when they were switched from pellets to powder. These results were somewhat surprising because the acquisition and maintenance of schedule-induced polydipsia is conceived of as being primarily dependent on food deprivation, amount of food per reinforcement, and schedule of reinforcement (Falk, 1971). In fact, scheduleinduced polydipsia is known for its robust nature and persistence under a variety of other conditions (Shearon \& Allen, 1984; Wetherington, 1982). Consequently, we decided to pursue the issue, hoping that in the course of discovering why little drinking occurs in hungry rats fed powder on a schedule (powder rats), we might have a better understanding of why polydipsia occurs in hungry rats fed pellets on a schedule (pellet rats).

Funds for the research were supplied by the Alberta Mental Health Advisory Council to C. H. M. Beck. The valuable comments of Dallas Treit and the editorial reviewers are acknowledged. We thank Cecile Cochrane for preparation of the manuscript. Address correspondence to Charles H. M. Beck, Department of Psychology, Biological Sciences Centre, University of Alberta, Edmonton, Alberta T6G 2E9, Canada.
In Experiment 1, we demonstrated the basic phenomenon that powder rats on an FT 60 -sec schedule do not develop polydipsia, whereas pellet rats do. In Experiment 2, we buttressed the replication of the effect with the addition of massed food and omitted food control conditions for the assessment of polydipsia. In addition, we showed that changing the food from pellets to powder, and vice versa, changed the drinking behavior, in accordance with our preliminary observation. By utilizing several test and control conditions, we found that a number of factors can be discounted as contributing to the absence of polydipsia in the rats receiving powder, and that the critical factor is the level of oral activity associated with feeding occurring immediately after food delivery.

\section{EXPERIMENT 1}

The principal purpose of this experiment was to compare the development of schedule-induced polydipsia in hungry rats receiving powder or pellets on an FT $60-\mathrm{sec}$ schedule. To control for pellet-powder differences related to food qualities, such as nutrient content, flavor, and moisture content, the powder was prepared daily from freshly ground pellets. To control for the amount of food received per session (Falk, 1967; Reid \& Dale, 1983; Rosellini \& Burdette, 1980), two groups of rats receiving powder were tested. One group received less than the average daily session total of $2.25 \mathrm{~g}$ of pellets obtained by the pellet rats, and the other group received more.

\section{Method}

Animals. Twenty-four male Sprague-Dawley rats (Ellerslie, Alberta, substrain) were individually housed in animal quarters maintained at $22^{\circ} \mathrm{C} \pm 1^{\circ} \mathrm{C}$ and at $51 \%$ humidity. The photo period was 12:12 h, with the lights on at $0700 \mathrm{~h}$. At the beginning of the experiment, the rats were 9 weeks old and weighed an average of $222 \mathrm{~g}$. 
Apparatus. The test chamber, which measured $20 \times 23 \times 23 \mathrm{~cm}$, had opaque walls and a transparent ceiling. The floor was covered with fresh wood chip litter at the beginning of each session. A pellet dispenser delivered pellets automatically to a food tray that measured $2.5 \times 3 \times 2 \mathrm{~cm}$ deep and was located in the corner of one end wall. For powder sessions, the food tray was removed, revealing a 3.4-cm-diam feeder hole in which was recessed a 3-cm-deep feeder cup. A water dipper delivered a dipper-full of dry food powder automatically from a trough to a $0.8-\mathrm{cm}$-diam hole in the floor of the feeder cup. Selection of one of several different sized dippers permitted a desired amount of powder to be delivered in a given session. The food powder was prepared daily by grinding and screening (0.4-mm mesh) $45-\mathrm{mg}$ Noyes pellets. A water spout that protruded $1 \mathrm{~cm}$ into the chamber was located $7 \mathrm{~cm}$ above the floor and $15 \mathrm{~cm}$ lateral to the feeder cup-tray site. Dim red ambient light was provided by fluorescent lights covered with red Mylar film. The animal was observed through the ceiling of the chamber via a mirror mounted at $45^{\circ}$ to the chamber ceiling. A room fan provided air circulation and background noise (65 dB SPL).

Procedure. Two weeks before testing began, members of triads of animals matched for body weight were randomly assigned to one of three groups of 8 animals. During the following 2 weeks, the animals were adapted to daily handling and were food deprived to $80 \%$ of their ad-lib preexperimental body weights. Body weights were monitored daily. The animals were tested for 2450 -min sessions of FT 60 -sec food delivery. Animals in the pellet group received pellets (pellet rats), and animals in the other two groups received powder (powder rats). The pellet rats received $5045-\mathrm{mg}$ Noyes pellets in one session; since all pellets were eaten, each individual rat ate $2.25 \mathrm{~g}$ of food per session. The food dippers were selected for the powder rats so that one group received on the average less than $2.25 \mathrm{~g}$ per rat per session (low powder rats) and the other group received more than $2.25 \mathrm{~g}$ per rat per session (high powder rats). The amount of powder eaten by a rat was determined by subtracting the weight of the powder left after the session from the weight of the powder at the start of the session. Care was taken to collect spilled powder. Water was freely available during all sessions. The volume of water drunk was recorded at the end of each session to the nearest $0.1 \mathrm{ml}$. Testing was conducted between 0730 and $1600 \mathrm{~h}, 5$ days per week. During the experiment, supplemental amounts of Purina Rat Chow biscuits were provided after the test session to maintain the animals at $80 \%$ of their body weight.

Repeated measures analyses of variance (ANOVAs), with groups as the between factor and sessions as the within factor, were applied to the data. These factorial ANOVAs were supplemented by simple main effect ANOVAs where required. The Geisser-Greenhouse correction factor was used to adjust for heterogeneity of covariance (Greenhouse \& Geisser, 1959). Newman-Keuls tests $(p<.05)$ were used for comparison of groups within sessions and of sessions within groups.

\section{Results}

Figure 1 shows the mass of food eaten and the volume of water drunk per session by the three groups. Group comparisons within sessions suggest that the significant group main effect for the amount of food eaten per session $[F(2,21)=3945.16, p<.001]$ was due to the high powder group's eating more food than the pellet group and the low powder group's consuming less food per session than the pellet group. By contrast, the group effect for volume of water drunk per session $[F(2,21)=45.29$, $p<.001]$ was caused by the large amount of water drunk by the pellet group compared with that consumed by the two powder groups. The two powder groups did not differ from each other. A significant session effect $[F(4.5,95.5)$ $=37.29, p<.001]$ and interaction effect $[F(9.1,95.5)$
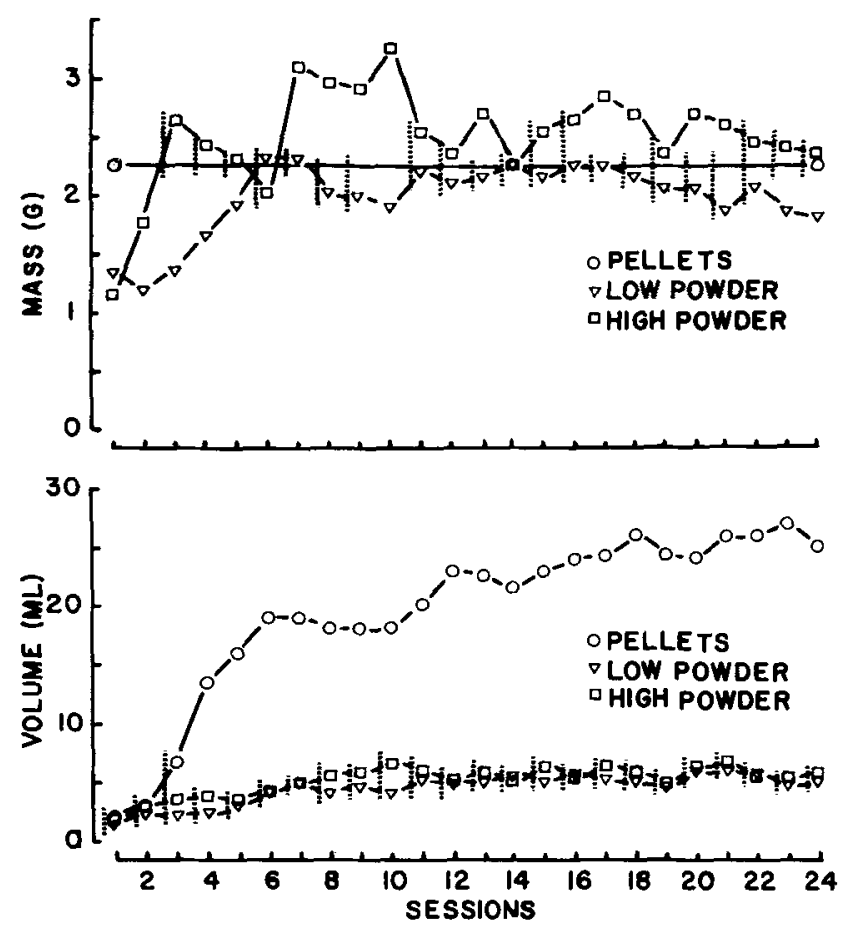

Figure 1. Mean grams of food eaten (upper graph) and mean milliliters of water drunk per session by rats receiving pellets (circles), the low amount of powder (triangles), and the high amount of powder (squares) on a fixed-time (FT) 60-sec schedule. For all groups, $n=8$. Means that are not linked by the same dotted line are signifcantly different (Newman-Keuls $p<.05)$. Standard errors are less than $15 \%$ of the means.

$=15.16, p<.001]$ were caused by the early large increase in the pellet rats' drinking and the absence of the same in the powder rats, as indicated by Newman-Keuls tests and by a nonsignificant simple main effects ANOVA of the sessions factor in the two powder groups.

Toward the end of training, a greater absolute range of individual differences in the volume of water drunk per session was seen in the pellet rats than in the powder rats. For example, over the last 10 sessions, the range of mean individual scores was 17.74 to $33.55 \mathrm{ml}$ for the pellet group and 3.41 to $10.27 \mathrm{ml}$ for the powder group. In spite of these within-group differences between individuals, over the last 10 trials, the powder rat drinking the most water, G41, drank less than the pellet rat drinking the least water, $\mathrm{G} 40$ (Mann-Whitney $U=7, p=.003$ ).

There were few significant within-session correlations found between the amount of food eaten and the volume of water drunk by the powder rats, and these showed no discernible pattern (data not presented).

Milliliters of water drunk per pellet or per gram of food eaten has been used as a measure of polydipsia (Rosellini $\&$ Burdette, 1980). An ANOVA of this measure produced the same pattern of effects as that described for the volume measure [i.e., group effect, $F(2,21)=39.02, p<.001$; session effect, $F(4.2,86.9)=30.73, p<.001$; and group $\times$ session interaction, $F(8.3,86.9)=14.61, p<.001]$. 
In lieu of a figure showing the group scores on all sessions, the means and standard errors on the first three sessions and last three sessions, respectively, were as follows: pellet group, $1.72 \pm .58 \mathrm{ml} / \mathrm{g}$ and $11.84 \pm$ $1.07 \mathrm{ml} / \mathrm{g}$; high powder group, $1.28 \pm .53 \mathrm{ml} / \mathrm{g}$ and $2.29 \pm .25 \mathrm{ml} / \mathrm{g}$; low powder group, $1.44 \pm .51 \mathrm{ml} / \mathrm{g}$ and $2.71 \pm .29 \mathrm{ml} / \mathrm{g}$.

\section{Discussion}

The rats that received pellets showed a drinking pattern characteristic of schedule-induced polydipsia. Over the first 10 sessions, their drinking increased to more than four times that observed in the initial sessions (Falk, 1971; Sanger \& Blackman, 1975). At asymptote, they drank more than $10 \mathrm{ml}$ of water per gram of food eaten (Cook, Wallace, \& Singer, 1983; Flory, 1971). The pellet rats' excessive drinking developed gradually over the sessions and was persistent once it developed (Sanger \& Blackman, 1975; Wetherington \& Riley, 1986). By contrast, the animals that received powder in Experiment 1 did not become polydipsic according to these measures. At asymptote, they drank less than $3 \mathrm{ml}$ per gram of food eaten and did not increase their drinking significantly from that of the initial sessions.

Several factors can be discounted as influencing the failure of the powder rats to develop polydipsia. It might be argued that although the powder rats did not significantly increase their drinking over the 24 days of testing, they were simply developing polydipsia more slowly. Rats fed pellets under the same levels of food deprivation and schedules of reinforcement develop polydipsia within 5 to 12 days (Falk, 1971). A twofold to fivefold longer test series provides an adequate challenge to this infinitely regressive argument.

Food-related factors, such as nutrient content, flavor, and moisture content, may be discounted because the powder was made from freshly ground pellets. If the amount of food eaten was the critical variable, extrapolating from the literature on pellet polydipsia generated by schedules with $60-\mathrm{sec}$ interpellet intervals, one would expect that the reduced drinking per gram of food eaten by the powder rats was caused by their consuming more food than the pellet rats (Falk, 1967; Reid \& Dale, 1983). Neither the correlational nor the ANOVA results bore out this conjecture. However, the results do not contradict the earlier reports, because those effects were caused by two- to sixfold increases in the amount of food.

Finally, it cannot be argued that the low average level of drinking by the powder rats was due to a few atypical rats that drank no water while the rest drank polydipsically, because there was no overlap in the volume drunk at asymptote by pellet and powder rats. However, large individual differences in the levels of polydipsia in rats receiving pellets have been reported (Mittleman \& Valenstein, 1985). Indeed, at asymptote in Experiment 1, there was a greater than two-fold difference between the largest and smallest amounts drunk by individual pellet rats. There is thus a possibility that the powder rats differed from the pellet rats because of an unintended selection bias. In Experiment 2, this concern was addressed by using animals as their own controls. This paradigm also provided a control for inadvertent differences between groups in housing, handling, and food deprivation.

\section{EXPERIMENT 2}

The general purpose of Experiment 2 was to determine why the pellet rats in Experiment 1 drank more water than the powder rats. An overriding concern was to restrict as much as possible the variance due to individual differences. Since pilot work had demonstrated that the pellet-powder group difference in drinking was robust enough that animals would return readily to stable baseline performance, a paradigm that alternated test and baseline conditions was adopted. The same animals were used throughout Experiment 2 in a series of nine test conditions. In addition, a detailed ethological analysis of behavior was used to address the issues raised by the following specific experimental hypotheses. The first five hypotheses pertain to the dependent measure-volume of water drunk-and the remainder to other dependent measures.

\section{Replication Equated for Food \\ Delivery Mechanism}

It is possible that the difference in drinking between the two groups in Experiment 1 was an artifact of selection and could not be replicated. This hypothesis was assessed in the acquisition condition in which the development of drinking in a group of randomly selected naive hungry rats receiving pellets on an FT 60 -sec schedule was compared with that of a similar group receiving scheduled powder.

In Experiment 1, the delivery of pellets was accompanied by an acoustically more intense solenoid firing than was the delivery of powder. Such additional auditory stress might have differentially potentiated the drinking of the pellet rats (Mittleman, Jones, \& Robbins, in press; Tazi, Dantzer, Mormede, \& Le Moal, 1986). In Experiment 1 , the powder was delivered by a dipper to an unlit 3-cm deep feeder cup, whereas the pellets were delivered to an open unshaded tray. Powder rats were able to bury their heads to beyond their eyes in the feeder cup. Rats prefer darkened chambers when stressed (File \& Peet, 1980; Lorenzini, Bucherelli, \& Giachetti, 1986). Therefore, it is possible that the absence of a feeder hole in the cage of the pellet rats augmented their stress levels and their drinking. To control for these extraneous stress factors in the acquisition condition, the mechanisms for the delivery of powder and pellets were equated for operational noise, vibration, and appearance.

\section{Replication with Animals as \\ Their Own Controls}

If large individual differences in schedule-induced polydipsia (Mittleman \& Valenstein, 1985; Experiment 1 of the present study) did not account for the group differences in drinking by the powder and pellet rats, then it 
should be possible to demonstrate the effect by using animals as their own controls. In the reversal condition, the group receiving pellets in the acquisition condition was switched to powder, and vice versa. The outcome would have important theoretical implications as well. If the reversal condition were to produce an abrupt drop in the drinking of the previously polydipsic animals, this would challenge the convention that such behavior is primarily dependent on food deprivation and schedule of reinforcement (Falk, 1967).

\section{Excessiveness of Drinking}

Massed-food and no-food conditions have been utilized as control conditions for assessing the excessiveness of schedule-induced drinking (Roper, 1981). It is possible that even though the powder rats drank less than the pellet rats in Experiment 1, rats served scheduled powder might drink significantly more than those served massed powder. Given such an outcome, the powder rats would be defined as polydipsic. In the massed-food condition, the rats received their total sessional food ration in a tray at the start of the session.

In the omitted-food condition, no food was delivered on selected intervals of the schedule of reinforcement. The water licking of rats showing pellet polydipsia is similar in no-food intervals of omitted-food conditions to that in no-food conditions (Roper, 1981; Roper, Edwards, \& Crossland, 1983). If rats receiving powder truly are not polydipsic, then their drinking under schedule should be the same as their drinking in the massed-food condition and in the no-food intervals of the omitted-food condition. In addition, their drinking in the food and no-food intervals of the omitted-food condition should be the same. By contrast, the pellet rats should switch back and forth between polydipsic and nonpolydipsic behavior depending on whether or not they receive food in the interval (Roper et al., 1983).

\section{Limited Access to the Food Dipper}

Unquantified observations suggest that during powdered food consumption, the surface bearing the powder is licked frequently, whereas there is little oral contact with the surface during the eating of pellets (Cooper \& Francis, 1979; unpublished observations in this laboratory). It is possible that the excessive licking of the water spout observed in rats made polydipsic by the scheduled delivery of pellets would be reduced by replacing pellets with a dry food that required licking to ingest it. If so, drinking by the rats on scheduled powder should increase if their opportunity to continue to lick the food dipper was cut short soon after food delivery. This was tested in the limits condition by withdrawing the food dipper $7 \mathrm{sec}$ after food delivery. Access to water was also prevented in both the pellet and the powder groups until the eating by the powder rats was finished. This equated the groups for duration of access to water. This maneuver was not expected to change the volume drunk by the group receiving pellets, because delaying access to water does not affect scheduled-pellet-induced polydipsia (Flory \& O'Boyle, 1976).

\section{Granular Food}

In the foregoing conditions, the powdered food was composed of granules less than $0.4 \mathrm{~mm}$ in diameter, whereas the pellets were $4.0 \mathrm{~mm}$ in the largest dimension. If water spout licking is reciprocally related to food licking, it should be possible to increase the drinking of the powder rats by giving them a more coarsely textured food that produces less licking. In preliminary tests, it was found that a food with a granular range between 0.4 and $1.2 \mathrm{~mm}$ was coarse enough to reduce the time spent licking the food-bearing substrate to $50 \%$ of that observed with powder and yet fine enough to require licking movements characteristic of powder but not pellet ingestion. In the granular condition, rats previously fed powder and pellets were presented with the scheduled delivery of a granular food for five sessions. The size of the food particles was of the range just mentioned. The possibility that the rats receiving granular food would drink excessively was assessed in part with a massed-food condition.

The preceding five hypotheses concerning why the animals that received pellets on schedule drank more than those that received powder, were addressed by the dependent measure, volume of water consumed. The following hypotheses involve other measures of drinking and nondrinking behavior.

\section{Feeder Poking and Licking}

An assumption underlying the hypotheses about the limits condition and the granular condition is that licking of the food-bearing surface is reciprocally related to water spout licking, and thus to drinking volume. The behavioral categories of putting the head into the feeder hole (feeder poking) and licking the water spout (licking) were included in an ethological analysis of the behavior. If the assumption is correct, then the time spent engaged in feeder poking and licking should be negatively correlated in those portions of the interval when most of the drinking occurs.

\section{Eating and Oral Contact with Surface}

The feeder poke hypothesis begs the question of exactly what the animals were doing in the feeder hole. Dissociation of time spent in licking food from that spent in contact with the food-bearing surface was not possible in scheduled sessions because the feeder hole casing was opaque. The mechanics of consumption were studied in two ingestion conditions in which all rats were presented with simultaneous equal amount of two different foods in open trays. In the first ingestion condition, powder and pellets were compared, and in the second ingestion condition, powder and pellets were compared with granular food in two separate tests. It was expected that the three foods would be ranked pellet, granular, and powder in order of increasing time to consume, reflecting decreasing particle size. If scheduled drinking is reciprocally related to nonregulatory oral behavior, then powder 
should produce more time in contact with the food tray after the food is gone than should pellets. The ranking of granular food relative to powder and pellets in the traycontact category should be predictable from the ranking of the foods in schedule-induced drinking.

\section{Excessive Behavior}

It is possible that even though the rats fed powder on schedule did not drink excessive volumes of water, they may have engaged excessively in some other behavior, such as feeder poking. Conditions not expected to show excessive behaviors included the earliest session of the acquisition condition, the massed-food condition, and the no-food intervals of the omitted-food condition. These behaviors were contrasted with behavior in the asymptotic sessions of the acquisition and reversal conditions and with that of the food intervals of the omitted-food condition. The same comparisons were made for the rats receiving pellets, because these data provided a check on the volumetric findings and an opportunity for corroboration with the literature.

\section{Time Course of Behaviors in the Interval}

Scheduled-pellet-induced polydipsia is characterized by drinking early in the food delivery interval as well as by excessiveness (Staddon, 1977). The hypothesis of an absence of schedule-induction effects in the powder rats would predict that most drinking would occur in the middle of the interval, along with other facultative behaviors, such as grooming, rearing, and locomotion (Staddon, 1977). The behaviors occurring in midinterval would not be expected to change over sessions; however, schedule control would be expressed in adjustments of terminal behaviors occurring in anticipation of food delivery (Roper, 1981).

\section{Heightened Arousal}

If the rats that received the scheduled delivery of powder behaved normally, then perhaps they did not experience the high level of arousal characteristic of rats exhibiting scheduled-pellet-induced polydipsia. Excessive drinking, chewing, licking, or grooming and high plasma corticosteroid levels provide evidence of heightened arousal in such rats (Cook \& Singer, 1976; Falk, 1967; Mittleman et al., in press). Since these aroused rats show the corticosteroid effect at the beginning of the session, it should be possible to demonstrate the putative difference in arousal in rats with a history of scheduled powder versus pellet reinforcements, outside of the scheduled regime. Comparing the two groups in a massed-food condition would seem appropriate, since that would prevent the confounding of arousal effects and session-specific schedule-induction effects. Animals aroused by an injection of amphetamine show increased rearing and locomotion (Fray, Sahakian, Robbins, Koob, \& Iversen, 1980). Thus, in the massed-food condition, one would expect higher frequencies of rearing and locomotion in the pellet rats than in the powder rats.
The hypothesis of differences in arousal in the two groups of rats presupposes differences in the arousalinducing capability of powder and pellets. Since preference is one measure of such an attribute, it is significant that rats have been found to prefer pelletized to powdered food (Naim, Brand, Christensen, Kare, \& Van Buren, 1986). However, the food used in Naim et al.'s study differed in nutrient content, particle size, and amount per session from that used in the present study. Consequently, the two ingestion conditions already described were used to assess preference for the pellet, powder, and granular food. It was predicted that all animals would show preference for pellets over powder by showing precedence in the time spent eating and precedence in the amount of ingestion for pellets relative to powder. The ranking of the precedence measures for granular food relative to powder and pellets would be predictable from the ranking of the foods in the schedule-induced drinking.

\section{Method}

Animals. Sixteen naive rats were used. At the beginning of the experiment, the rats were 9 weeks old and weighed an average of $227 \mathrm{~g}$. All other particulars were as in Experiment 1.

Apparatus. The apparatus was identical to that of Experiment 1, with the following exceptions. The pellets were delivered from the pellet dispenser to the dipper via a tube while the dipper was in a retracted position below the floor of the food cup. The dipper then rose through the floor of the food cup, presented the rat with the food, and remained available for the rest of the 60-sec interval. Viewed from inside the chamber, the presentation of the pellet was identical to that of the presentation of the powder. The accompanying sounds and vibrations were the same, because both the solenoid for the pellet dispenser and the solenoid for the dipper fired on every food delivery. The pellet dispenser was empty on powder trials, and the powder trough was empty on pellet trials. A 25-W red light bulb mounted $23 \mathrm{~cm}$ above the chamber provided illumination. A microcomputer (IBM PC/XT) with a clock accurate to .01 $\mathrm{sec}$ was used in the coding of live and videotaped behavior.

Procedure. One week before testing began, members of pairs of rats matched for body weight were randomly assigned to one of two groups of 8 animals. During the week, the animals were adapted to daily handling and were food deprived to $80 \%$ of their ad-lib preexperimental body weights. Body weights were monitored daily.

The animals were treated individually to the following experimental conditions in the same order:

Acquisition. In Sessions 1-10, Group Pellet-Powder (PEPO) received food pellets and Group Powder-Pellet (POPE) received food powder on an FT 60-sec schedule. This condition was a direct replication of Experiment 1.

Reversal. In Sessions 11-17, Group PEPO received powder and Group POPE received pellets on an FT 60-sec schedule. The reversal condition permitted the replication of Experiment 1 using the animals as their own controls.

First massed food. This condition provided control data for the definition of the excessiveness of schedule-induced effects. In this condition, conducted on Session 18, a $2.5 \times 3 \times 2 \mathrm{~cm}$ deep food tray was fitted over the feeder hole. POPE rats received $2.25 \mathrm{~g}$ of pellets and PEPO rats received $2.25 \mathrm{~g}$ of powder in the tray at the start of the session.

Control. For this condition, on Sessions 19, 21, 25, 27, 33, 35, 37,39 , and 40 , the food tray was removed. Group PEPO received powder and Group POPE received pellets on an FT 60-sec schedule, as in the reversal condition. 
Omitted food. In Session 20, Group PEPO received powder and Group POPE received pellets in 35 of the 50 intervals of the FT 60 -sec schedule and no food in the remaining intervals. The nofood intervals in this condition provided control data for the definition of the excessiveness of schedule-induced effects.

Limits. This condition, presented on Sessions 22, 23, and 24, was designed to determine if the rats fed powder would become polydipsic if their access to the food-bearing substrate was restricted The water spout was retracted from the chamber at the time of food delivery. As rats required no more than $7 \mathrm{sec}$ to consume the food powder (unpublished observation), $7 \mathrm{sec}$ after food delivery, the food dipper was retracted and the water spout was returned. Thirty seconds after food delivery, the food dipper was returned empty. The POPE rats received pellets and the PEPO rats received powder on an FT 60-sec schedule. The amount of powdered food eaten per session by the PEPO rats was weighed to ensure that they were eating approximately $2.25 \mathrm{~g}$ per session.

First ingestion. The mechanics of consumption of different foods were compared in this condition. The apparatus was modified to include a second tray identical to that used in the massed-food condition. In the first ingestion condition, on Session 26, all rats received 25 pellets in one tray and $1.125 \mathrm{~g}$ of powder in the other tray at the beginning of the session.

Granular. The effects on drinking and other behavior of food of a particle size intermediate to pellets and powder were observed. On Sessions 28-32, all rats received approximately $45 \mathrm{mg}$ of granular food per reinforcement. The granular food was prepared by crushing and sieving pellets. The particle sizes ranged between $0.4 \mathrm{~mm}$ and $1.2 \mathrm{~mm}$. All other procedures in the limits and granular conditions were identical to those of the acquisition condition.

Second massed food. On Session 38, the same procedures as in the first massed-food test were utilized, except that all rats received $2.25 \mathrm{~g}$ of granular food in the tray.

Second ingestion. On Sessions 34 and 36, all rats received two massed-food presentations, one of $1.125 \mathrm{~g}$ of powder and $1.125 \mathrm{~g}$ of granular food and the other of 25 pellets and $1.125 \mathrm{~g}$ of granular food in two separate trays. The sessional order of the two-food tests was counterbalanced across sessions. The type of food loaded into the particular tray was determined in a random fashion for the individual animal and counterbalanced across animals. Water was freely available during all sessions.

Measures. Testing was done between 0830 and $1600 \mathrm{~h}$. Time of day of testing was counterbalanced for the animals in the two groups. Each session lasted for $50 \mathrm{~min}$. The volume of water drunk was recorded at the end of each session to the nearest $0.1 \mathrm{ml}$.

The behavior of the animal was coded by an observer on Sessions 1, 4, 7, and 10 of the acquisition condition; on Sessions 11, 14 , and 17 of the reversal condition; on all remaining experimental sessions; and on the control conditions of Sessions 21 and 40. The coding was done during five 6-min observation trials preceded by an initial 2-min and a terminal 2-min period without observation. The intertrial interval was $4 \mathrm{~min}$. These coding trials were used on all conditions except the second massed-food condition and the two ingestion conditions. In these conditions, the coding was restricted to one trial of $15 \mathrm{~min}$ at the start of the session because the food was entirely consumed within that time. In the omittedfood condition, no food was delivered on a randomly selected subset of half of the 30 intervals occurring during the observation trials.

The microprocessor was programmed to store the code of each keyboard entry made by the observer and its time of occurrence. Mutually exclusive and comprehensive categories were used to code seven types of behavior of the rat and the rat's presence in three spatial zones of the chamber. The three zone categories were food area, the rat's forequarters in the chamber quadrant containing the feeder hole; water area, the rat's forequarters present in the quad- rant containing the water spout; and other area, the rat's forequarters present in the remaining half of the chamber. The seven behavior categories were licking, the licking of water from the spout; feeder poking, engaging in oral and perioral activity while the nose is in the feeder hole; rearing, raising the forepaws above a line $8 \mathrm{~cm}$ above the floor; locomoting, forequarters entering a chamber quadrant; grooming, sniffing, washing, combing, licking or scratching itself; being immobile, sitting or lying without bodily movement; and investigating, any movements not involved in the other behaviors. These categories were used in the acquisition, reversal, and omitted-food conditions. In the massed-food and ingestion conditions, feeder poking was replaced with two categories, eat (eating food) and tray (oral and perioral contact with the food tray while not eating). Contact with the tray consisted of $90 \%$ oral contact (i.e., licking and chewing) and $10 \%$ perioral contact (i.e., sniffing; unpublished observation).

There was greater than $85 \%$ agreement on all measures of all behaviors on selected sessions coded from tape by two independent observers. To further ensure replicability, the coding of specific rats on specific sessions was assigned randomly in a counterbalanced manner to two independent observers. In analyzing the data, each occurrence of a behavior was defined as a response. A bout was defined as a series of consecutive responses in which occurrences of the same behavioral response were separated by the response of a different behavior. Several measures of the behaviors were used, specifically bour frequency (BF), the number of bouts of a behavior per trial; percent time (PT), the percentage of total time in a trial devoted to a behavior; and transformed mean bout duration (BD), in which the transformation was the square root of the $\mathrm{BD}$ score in seconds plus 1 . The data were transformed to normalize the distribution of $\mathrm{BD}$ scores. In addition, the mean time spent on each behavior per 6-sec bin in the 60-sec interfood delivery interval was computed. A repeated measures ANOVA, with groups as the between factor and sessions, bins, or trials as the within factor, was applied as appropriate to each measure of each behavior. The Geisser-Greenhouse correction factor and Newman-Keuls test were used as in Experiment 1. Measures of central tendency in the text are means and standard errors.

\section{Results and Discussion}

Replication equated for food delivery mechanism. The acquisition condition was designed to test whether the group difference in drinking was replicable and whether it was dependent on incidental features of the delivery mechanism.

The volume of water drunk per session increased over the 10 sessions of the acquisition condition in the PEPO rats compared with that in the POPE rats, as indicated by the group and interaction effects (see Table 1 and Figure 2). Within-session Newman-Keuls comparison of the groups indicated that in early sessions the two groups did not differ, whereas in later sessions they did (see Figure 2). Within-group across-session Newman-Keuls showed that the pellet rats increased their drinking repeatedly across successive sessions (i.e., between Sessions 2 and 3,4 and 5,5 and 7,7 and 9, and 8 and 10). By contrast, the powder rats showed no increases in drinking (Figure 2).

To sum up, these data replicate those of the first 10 sessions of Experiment 1 . The results suggest that the greater volume of water drunk by rats receiving scheduled deliv- 
ery of pellets compared with those receiving powder is not an artifact of group selection and is not due to differences in the food delivery mechanisms.

Replication with animals as their own controls. If the difference in drinking between the groups was the result of individual differences and selection bias, then the null hypothesis would not be rejected by using the animals as their own controls.

The switching of the food treatments in the reversal condition resulted in a reversal of the groups' drinking behavior, as seen in Figure 2 and as attested by the group and group $\times$ session effects (see Table 1). The drop in volume drunk per session by the rats switched to powder was asymptotic in the first session of the reversal condition. This abrupt reduction in drinking occurred in all the PEPO rats, as illustrated by the percentage change in volume drunk scores between Sessions 10 and $11(M=$ $77 \%$, range $=61 \%-83 \%$ ). Fully enhanced drinking appeared in the second session of pellet delivery in the POPE rats (see Figure 2).

The results confirm the conclusions derived from the acquisition condition that the phenomenon is replicable. The data suppport the contention that the pellet-powder effect is not the result of individual differences. The results also provide an impressive demonstration of the power of the type of food presented to abruptly terminate the otherwise extremely persistent polydipsic response (Wetherington \& Riley, 1986). If the extinction of an associatively conditioned appetitive response or the acquisition of a conditioned avoidance response were involved, one would expect a more gradual decline in drinking. A model of polydipsia based on adventitious learning would require one or the other of these gradual processes (Falk, 1971). Rather, the rapidity of the decline in drinking suggests that the effect was caused by the removal of an eliciting stimulus, as would be the case with sensitization (Wetherington, 1982). The loss of polydipsia in the rats

Table 1

$F$ Values for the ANOVA of Volume Drunk per Session

\begin{tabular}{lcccc}
\hline \multicolumn{1}{c}{ Condition* } & Effect & & $d f$ & $F$ \\
\hline Acquisition (1-10) & G & 1,14 & $46.91^{* *}$ \\
& G $\times S$ & $2.5,35.5$ & $5.79 \S$ \\
Reversal (11-17) & G & 1,14 & $19.3^{* *}$ \\
Massed (18)-Reversal (17) & $\mathrm{G} \times \mathrm{S}$ & $3.7,52.2$ & $10.71^{* *}$ \\
Omitted (20)-Control (19) & $\mathrm{G}$ & 1,14 & $52.3^{* *}$ \\
& $\mathrm{G} \times \mathrm{S}$ & 1,14 & $24.68^{* *}$ \\
Limits (22-24) & $\mathrm{G}$ & 1,14 & $22.97^{* *}$ \\
Granular (28)-Control (27) & $\mathrm{G}$ & 1,14 & 14.098 \\
& $\mathrm{G} \times \mathrm{S}$ & 1,14 & $67.88^{* *}$ \\
Granular (32)-Control (33) & $\mathrm{G}$ & 1,14 & $6.32 \ddagger$ \\
& $\mathrm{G} \times \mathrm{S}$ & 1,14 & $61.05^{* *}$ \\
Granular (32)-Massed (38) & & & \\
POPE Rats & $\mathrm{S}$ & 1,14 & $53.1^{* *}$ \\
PEPO Rats & $\mathrm{S}$ & 1,14 & $51.2^{* *}$ \\
\hline
\end{tabular}

Note-Massed $=$ massed food. Omitted = omitted food. Granular = ganular food. *Numbers are session numbers. $\neq \mathrm{G}=$ group, $\mathrm{S}=$ session. $\ddagger p<.05 . \quad \S p<.01 .{ }^{* * p}<.001$.
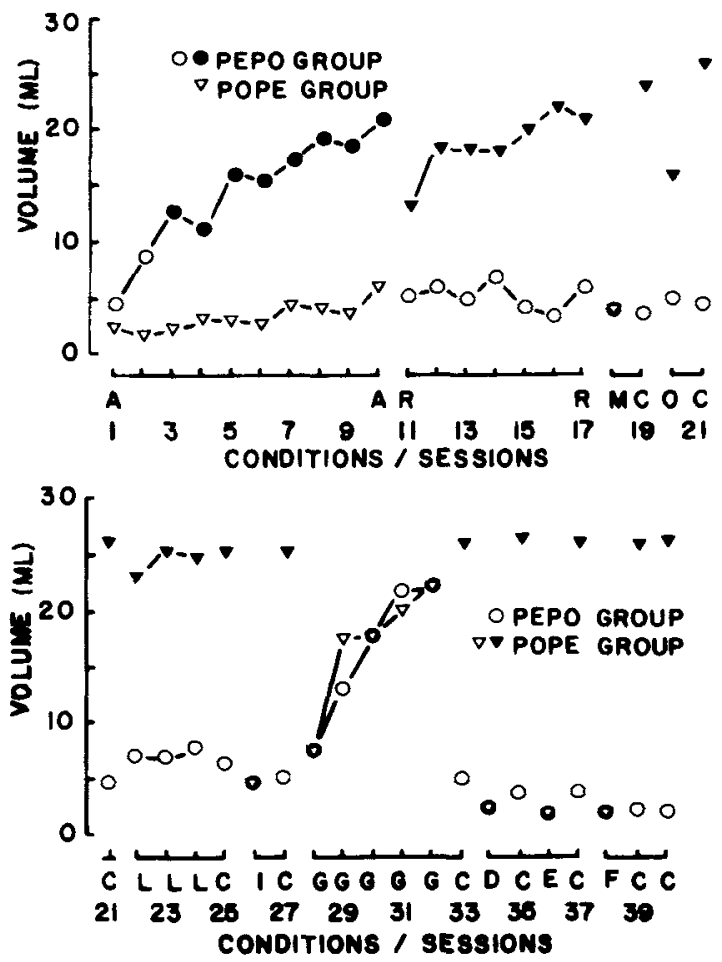

Figure 2. Mean volume of water drunk in milliliters per session by rats in Group Pellet-Powder (PEPO; circles; $n=8$ ) and in Group Powder-Pellet (POPE; triangles; $n=8$ ). $A=$ acquisition condition, $\mathbf{R}=$ reversal condition, $\mathbf{M}=$ massed powder-pellet cendition, $\mathbf{C}=$ control condition, $L=$ limits condition, $I=$ powder versus pellet ingestion condition, $\mathbf{G}=$ granular condition, $\mathbf{D}=$ powder versus granular ingestion condition, $\mathbf{E}=$ pellet versas granular ingestion condition, $\mathbf{F}=$ massed granular condition. Significant (NewmanKeuls, $p<.05$ ) group effect within a session is indicated by a filled symbol. Standard errors are less than $15 \%$ of the mean values.

switched to scheduled powder was more abrupt than the acquisition of polydipsia in the rats switched to pellets. This was because removal of the eliciting stimulus, the pellets, was involved in the first case, and acquisition of sensitization was involved in the second. Some factor predisposing the later group to sensitization may have been present because the rats switched to pellets developed polydipsia more quickly than is usual (Sanger \& Blackman, 1975; present study). Possible factors include the longer history of food deprivation and the exposure to the schedule, a schedule control effect (Roper, 1981).

Excessiveness of drinking. If the rats receiving powder truly were not polydipsic, their drinking in scheduled sessions should be the same as that in the massed-food condition. Drinking in the omitted-food condition should be reduced in proportion to the reduction of food delivered.

The volume of water drunk by both groups in Session 18, the first massed-food session, was not significantly different from the amount drunk by animals receiving powder in scheduled feedings in the acquisition, reversal, and control conditions (Figure 2). In the massedfood condition, the pellet rats drank significantly less water than they did in the last session of the reversal con- 
dition (see Table 1 and Figure 2). Using control Session 19 as representative of current asymptotic scheduled performance, an ANOVA comparing volume drunk in Session 19 with that drunk in the omitted-food session produced a group effect and a group $\times$ session effect (see Table 1 and Figure 2). Newman-Keuls within-group comparisons produced no significant effects. Relative to the animals in the control session, the animals in the omittedfood condition experienced a $30 \%$ drop in the amount of food received. Concurrently, the animals receiving pellets showed a $35.17 \%+3.74 \%$ decrease and the powder rats a $17.28 \% \pm 5.53 \%$ increase in the volume of water drunk in the omitted-food condition compared with control Session 19.

The results support the hypothesis that the rats fed powder were not polydipsic in any of the comparisons made between the scheduled conditions and the massed-food condition or the omitted-food condition. The decline in volume drunk by the pellet rats in the omitted-food condition compared with that drunk in the scheduled condition is commensurate with the decreased amount of food received in the former condition, suggesting that the pelletfed rats were drinking very little in the no-food intervals. This result agrees with observations on time spent licking the water spout in an omitted-food condition by rats receiving pellets (Roper et al., 1983). The interval data on spout licking from the present study will be presented in a later section.

Limited access to the food dipper. If the licking of the food dipper prevented the development of excessive drinking in the powder rats, then removing the food dipper $7 \mathrm{sec}$ after food delivery should permit polydipsia to develop.

An ANOVA of volume drunk per session over Sessions 22-24 of the limits condition revealed only a group effect (see Table 1 and Figure 2). The volume of water drunk per session in the limits condition by each group did not change significantly from the amount the groups drank in the control conditions of Sessions 21 and 25. The amount of powder consumed per session in the limits condition by the PEPO rats was not different from the expected amount $(2.23 \pm .21 \mathrm{~g}$ vs. $2.25 \mathrm{~g})$.

The data show that restricting access to the food dipper had no effect on the volume of water drunk by the animals receiving powdered food. The effect of the maneuver on the time rats spent with their heads in the feeder hole is presented in a subsequent section. One would expect a decrease in that behavior if the foregoing hypothesis were correct.

Granular food. If water spout licking is reciprocally related to food licking, then the granular food should increase the drinking of the rats previously fed powder and decrease the drinking of those previously fed pellets.

An ANOVA revealed significant group and group $\times$ session effects in comparing the volume of water drunk in the control condition (Session 27) with that of the first session of the granular condition (Session 28; see Table 1 and Figure 2). Newman-Keuls tests showed that the interaction was due to a significant decrease in the volume of drinking by the POPE rats and no significant change by the PEPO rats. The volume of water drunk by the two groups did not differ over the five sessions of the granular condition (Figure 2). An ANOVA of two groups $x$ two sessions comparing the volume of water drunk per session on the last session of the granular condition (Session 32) with that of the control condition (Session 33) revealed a group effect and an interaction effect (Table 1 and Figure 2). The interaction was due to a significant decrease in the volume drunk by the PEPO rats and no significant change by the POPE rats.

The correlation between the volumetric scores of the POPE rats in the control condition (Session 27) and the final granular session was $r=.95(p<.01)$. The correlation between the volumetric scores of the PEPO rats in the final session of the granular condition and the acquisition condition was $r=.93(p<.01)$. No correlations of volumetric scores on granular Session 32 and sessions under scheduled delivery of powder were significant for either group.

The POPE and PEPO rats did not differ in the volume of water drunk in the massed granular food condition (Session 38; see Figure 2). The POPE and PEPO rats drank less in the massed granular condition than they did in the last session of the granular condition (Table 1 and Figure 2). The volume drunk in the massed granular condition did not differ in either group from that drunk by either group in the pellet-powder massed condition or from that drunk by the PEPO rats in the scheduled control sessions (Figure 2).

The results support the conclusion that rats can be made polydipsic relative to a massed-food condition by presenting granulated food on an FT 60 -sec schedule. It is clear that not being able to seize the food delivered in one mouthful and being required to ingest the food by licking does not preclude the development of polydipsia. The effect of granular food on head in the feeder hole is relevant to the issue of why granular food induced polydipsia. These data are presented as part of the next hypothesis.

The POPE rats had to reacquire the polydipsic response when introduced to granular food in spite of the recent history of pellet polydipsia. The data suggest some specificity in the polydipsia-eliciting properties of the food, a specificity that has been noted in other instances of sensitization (Lipsett \& Kaye, 1965; Ulrich \& Azrin, 1962). The high positive correlations between polydipsic drinking under scheduled pellets and under granular food suggests, first, that the two foods are engaging the same process and, second, that the individual differences are temporally and environmentally stable, as has been found to be the case with sensitization (Petrinovich \& Patterson, 1980).

The following five hypotheses address the issue of the difference between the groups, utilizing measures other than volume drunk.

Feeder poking and licking. If there is a reciprocal relation between drinking and feeder hole activity early in the interval, then feeder poking and licking should be complementary in the comparison of pellet and powder rats 
in scheduled sessions, in the comparison of powder rats in control and granular conditions, and in the correlations of the two behaviors across individual differences.

Within-group comparisons of the PEPO and POPE groups' feeding and drinking behavior illustrate the reciprocal relationship of the two behaviors. The data of the limits condition were collapsed across sessions because a three-way ANOVA of groups $\times$ sessions $\times$ bins showed that sessions had no effect. The PEPO and POPE groups differed in their patterns of feeder poking and of licking across the 106 -sec bins of the interfood interval for the pooled average of the three sessions of the limits condition (see Table 2 and Figure 3, upper graphs). Bins 2 and 3 were periods of excessive drinking by the pellet-fed rats (POPE). PEPO rats spent $60 \% \pm 3 \%$ more time engaged in feeder poking in Bin 2 and $22 \% \pm 1 \%$ more time engaged in feeder poking in Bin 3 than did POPE rats. Corresponding values for the last sessions of the acquisition and reversal conditions were, respectively, $85 \% \pm 6 \%$ for Bin 2 and $32 \% \pm 2 \%$ for Bin 3, and $78 \% \pm 4 \%$ for Bin 2 and $33 \% \pm 2 \%$ for Bin 3. The graphs for acquisition and reversal data at asymptote are not presented, because they show the same pattern of group differences as seen in the limits condition.

The effect of granular food on feeder poking and licking is visualized by contrasting the granular food treatment of the PEPO rats with their powder treatment under a control condition (Figure 3, lower graphs). For the PEPO rats, powdered food in control condition Session 21 induced a $60 \% \pm 5 \%$ increase in Bin 2 and a $25 \% \pm 2 \%$ increase in Bin 3 in feeder poking compared with granular food in Session 32. The ANOVA values for treatments and treatments $\times$ bins are given in Table 2 . The effect of the limits condition on feeder poking and licking of the rats fed powder is presented in the middle pair of graphs in Figure 3. An ANOVA showed no significant differences between PEPO rats in control condition Session 21 and limits condition Session 24 on these behaviors. The limits condition decreased feeder poke of PEPO rats (compared with the control condition) by only $17 \% \pm 1 \%$ in Bin 2 and $11 \% \pm 1 \%$ in Bin 3 (Figure 3 ).
The PEPO rats kept their heads in the feeder hole after its retraction at $7 \mathrm{sec}$ into the interval (Figure 3).

Values of $r=-.93$ to $-.97(p<.01)$ were obtained for correlations of time spent licking the water spout with time spent poking into the feeder in Bins 2 and 3 of the control sessions and of the final sessions of the acquisition, reversal, limits, and granular conditions. Even though a large amount of time was spent in feeder poking toward the end of the food interval, this was not correlated with the time spent licking the water spout in the same portion of, or in any other portion of, the interval.

These results support the hypothesis that poking into the feeder hole in the early part of the interval is reciprocally related to the time spent licking the water spout. The power of the hypothesis derives from its ability to account for the differences in drinking in the powder and pellet rats in scheduled sessions and the absence of such differences in massed-food sessions, and to explain the failure of the limits condition to induce polydipsia in the powder rats and, conversely, the success of the granular condition in this respect. Observations supporting this hypothesis were reported in a study using the amount of food delivered on schedule of reinforcement to manipulate drinking (Reid \& Dale, 1983). A reciprocal relationship was noted between poking the head in the feeder hole early in the interval and the amount of drinking. The increase in feeder poking was greater than that necessary for the consumption of the larger amounts of food. This supports our finding that in the limits condition, the rats kept their heads in the feeder hole even after the dipper bearing the powder had been retracted. The present results permit the dissociation of the findings of Reid and Dale from the effects of amount of reinforcement. This broader currency is important because it frees one from having to consider the confounding osmotic and absorptive effects of increased food mass on tissue fluid balance and on subsequent drinking. It raises the interesting possibility that the antipolydipsic effects (in milliliters per gram of food eaten) of increased amounts of liquid reinforcement (Falk, 1967) and of solid food reinforcement (Falk, 1967; Flory, 1971) may be explained by the same principles.

Table 2

$F$ Values for the ANOVA Time (in seconds per 10-sec bin) for Oral Behaviors

\begin{tabular}{|c|c|c|c|c|}
\hline Condition* & Behavior $f$ & Effect $\ddagger$ & $d f$ & $\boldsymbol{F}$ \\
\hline \multirow[t]{2}{*}{ Limits (22-24) } & Feeder Poke & $\underset{\mathbf{G} \times \mathbf{B}}{\mathbf{G}}$ & $\begin{array}{c}1,14 \\
2.4,33.3\end{array}$ & $\begin{array}{l}9.268 \\
7.02 \S\end{array}$ \\
\hline & Lick & $\underset{\mathbf{G} \times \mathbf{B}}{\mathbf{G}}$ & $\begin{array}{c}1,14 \\
2.1,29.4\end{array}$ & $\begin{array}{l}20.63^{* *} \\
13.38^{* *}\end{array}$ \\
\hline \multirow[t]{2}{*}{ Granular (32)-Control (27) } & Feeder Poke & $\begin{array}{c}T \\
T \times B\end{array}$ & $\begin{array}{c}1,14 \\
2.6,36.3\end{array}$ & $\begin{array}{l}9.188 \\
9.49 * *\end{array}$ \\
\hline & Lick & $\begin{array}{c}T \\
T \times B\end{array}$ & $\begin{array}{c}1,14 \\
2.6,37.1\end{array}$ & $\begin{array}{r}15.64^{* *} \\
9.59^{* *}\end{array}$ \\
\hline Ingestion (26) & PO-PE Tray & $\mathbf{T}$ & 1,30 & $8.10 \S$ \\
\hline Ingestion $(34,36)$ & PO-G Tray & $\mathbf{T}$ & 1,30 & $7.77 \S$ \\
\hline
\end{tabular}

*Numbers are session numbers. †PO-PE tray = contact with tray containing powder or pellets. PO-G tray = contact with tray containing powder or granular food. $\ddagger G=$ group, $B=$ bin, $\mathrm{T}=$ food treatment. $\$ p<.01 .{ }^{* *} p<.001$. 


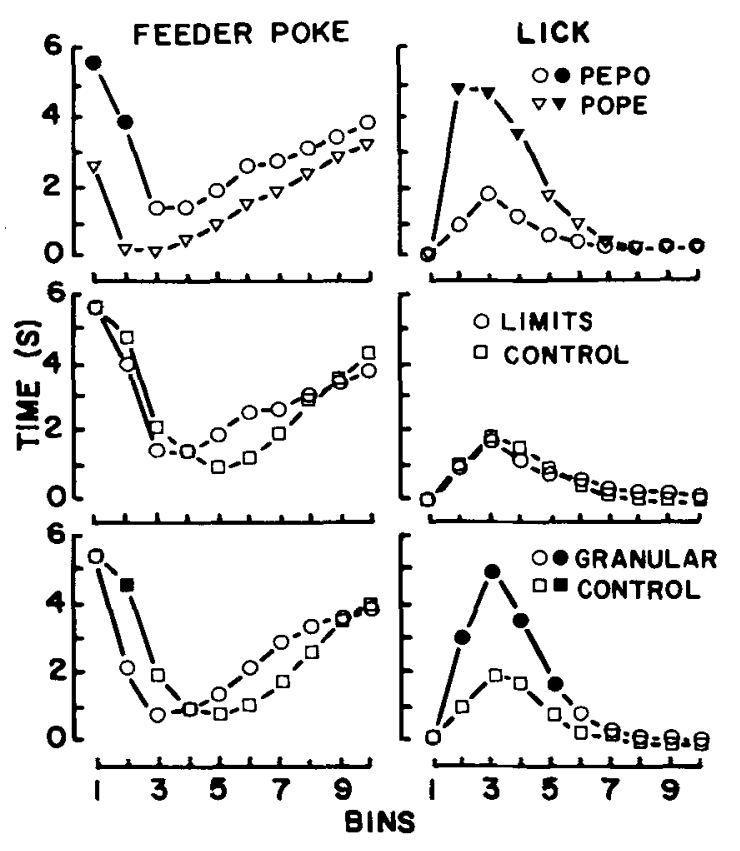

Figure 3. Mean time, in seconds per bin, over the 106 -sec bins of the interfood interval for feeder poke on the left and lick on the right in each pair of graphs. Top pair of graphs compares powder-pellet (POPE) rats (triangles, $n=8$ ) with pellet-powder (PEPO) rats (circles, $n=8$ ) on averaged scores of all three sessions of the limits condition. Middle pair of graphs compares the PEPO rats' behavior on the averaged limits condition, Sessions 21-24 (circles), with that on the control condition, Session 21 (squares). Bottom pair of graphs compares the PEPO rats' behavior on granular condition, Session 32 (circles), with that on the control condition, Session 21 (squares). Significant (Newman-Keuls, $p<.05$ ) group effect within a session is indicated by a filled symbol. Standard errors are less than $15 \%$ of the mean values.

Eating and oral contact with surface. If particle size affects rate of consumption, then the order of the three foods from the lowest to the fastest rates should be powder, granular food, and pellets. If drinking volume under scheduled conditions is reciprocally related to nonregulatory behavior, then the ranking of the foods on tray contact should be as follows: powder should require the longest time, with no difference between granular food and pellets.

Because the results of the first ingestion condition were in agreement with those of the second for powder and pellets, only the results of the second condition are presented when both conditions bear on the same point. The time to eat all of each food (in seconds) was $64.88 \pm 5.29$ for pellets, $108.00 \pm 6.72$ for granules, and $228.31 \pm 12.45$ for powder. There was no overlap of individual rats' scores for the three types of food. The time in contact with the tray (in seconds) was $10.75 \pm 1.52$ for the pellet tray, $22.56 \pm 2.88$ for the granular tray, and $44.31 \pm 7.53$ for the powder tray. An ANOVA of food treatment $\times 30$-sec bins showed that only the differences between the powder and the other two foods were significant (Table 2).
The time required to eat the granular food was approximately twice that for pellets, whereas the volume drunk in scheduled sessions was not different for the two foods. This suggests that although food composed of smaller particles takes longer to eat, this effect is not sufficient to account for differences in schedule-induced drinking produced by foods of different textures. The amount of nonregulatory oral behavior directed toward the foodbearing surface would appear to be a more critical variable. This conclusion supports the inference (Reid \& Dale, 1983; limits condition, present study) that nonregulatory oral activity in the feeder hole was critically related to schedule-induced drinking.

Excessive behavior. If the powder rats did not drink excessively, perhaps they engaged heavily in some other behavior (e.g., feeder poking).

Two-way ANOVAs of group $\times$ session or group $\times$ interval was done, comparing acquisition condition Session 1 with Session 10, reversal condition Session 17 with massed condition Session 18, and omitted condition food intervals with no-food intervals. The $F$ values for the interaction effects and the Newman-Keuls results of withingroup comparisons are shown, along with mean percent time per trial values in Figure 4. The food and no-food intervals of the omitted-food condition each totaled half of each trial. To assist comparison with the other condition, the percentages of the omitted-food condition are doubled. None of the comparisons on any of the behaviors produced significant effects for the powder-fed rats. By contrast, the pellet-fed rats showed increased licking in all three comparisons (Figure 4).

The results support the hypothesis that the rats fed powder show no evidence of schedule-induced excessiveness of behavior, whether the standard is massed food, no food, or early acquisition. The data on licking by pellet rats confirm the excessiveness reported for the volume measure and extend the effect to differences between food and nofood intervals within a session. The power of the presentation of food to elicit or not elicit drinking on an intervalto-interval basis is impressive. It supports the elicitatory aspect of the sensitization model rather than the associative conditioning models, and provides an elemental analogue for the abrupt sessional decline in drinking in the animals switched from scheduled pellets to powder.

Time course of behaviors in the interval. If the powder-fed rats did not show the effects of schelude induction, then, in contrast with pellet-fed rats, they should show no increases in behavior over sessions, early in the food delivery interval.

A two-way ANOVA of sessions $x$ bins in the acquisition condition provided within-group analysis of changes in each behavior. A comparison of Session 1 with Session 10 across the 106 -sec bins of the interfood interval is presented in Figure 5. For the powder rats, significant session $\times$ bin interactions were obtained for feeder poking, rearing, and locomoting (see Table 3). Inspection of the Newman-Keuls analysis indicates that these effects involve changes in terminal behaviors. The pellet-fed rats showed significant interaction effects for licking, feeder 

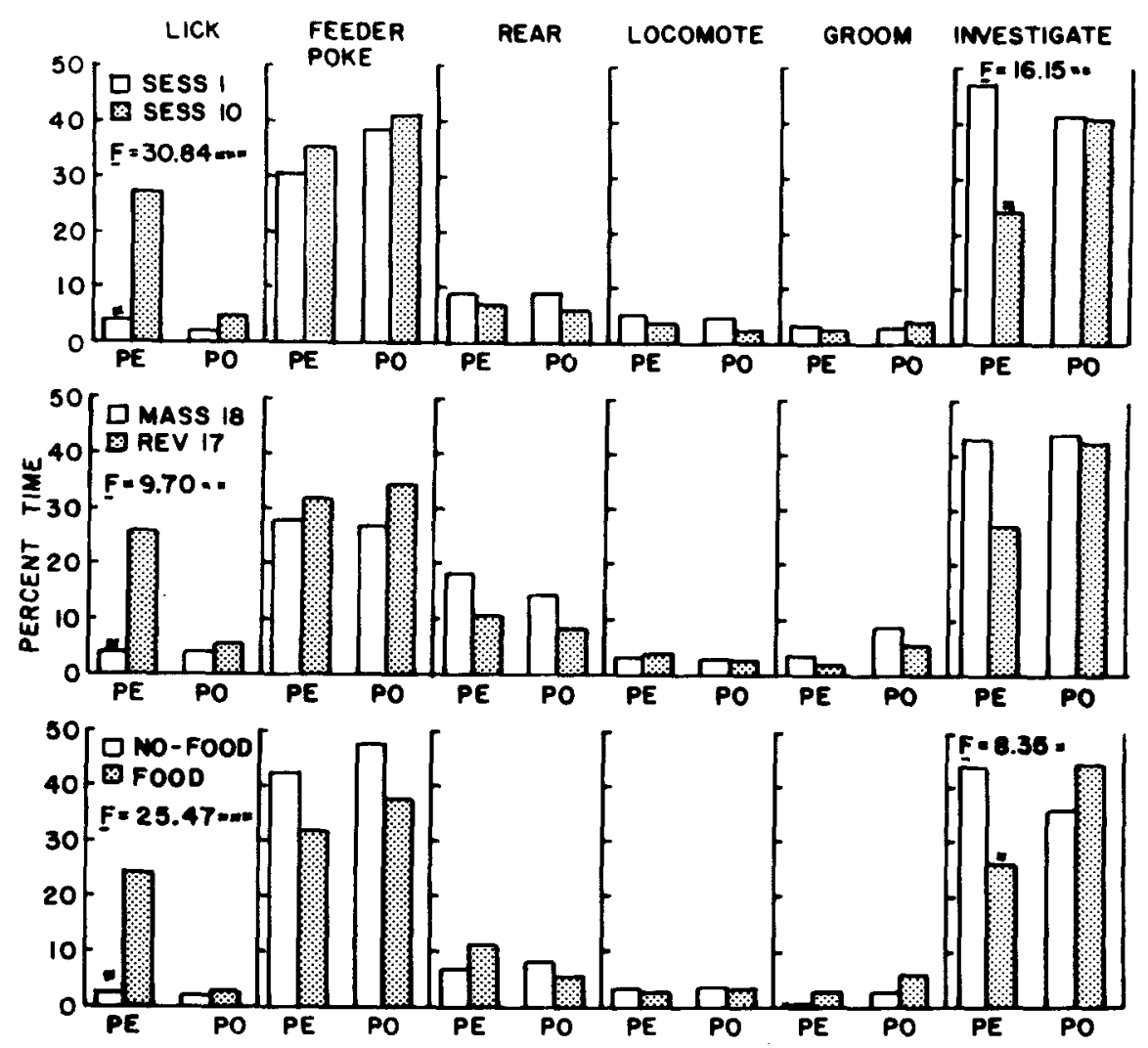

Figure 4. Mean percent time per trial spent in licking, feeder polking, rearing, locomoting, grooming, and investigating by rats receiving pellets (PE) and rats receiving powder (PO). Upper graphs present a comparison of Session 1 (clear bar) with Session 10 (stipled bar) of the acquisition condition. Middle graphs compare the massed food session (clear bar) with the last session of the reversal condition (stipled bar). Lower graphs contrast the no-food intervals (clear bar) with the food intervals (stipled bar) of the omitted food condition. $F(1,14)$ values are for group $X$ session interactions. Significant (Newman-Keuls, $p<.05$ ) session effects within groups are indicated on the lesser of the two means. Standard errors are less than $15 \%$ of mean values. ${ }^{*} p<.05 . * * p<.01$. $* * * p<.001$.

poking, rearing, locomoting, and investigating (Table 3). An early interval increase in drinking over sessions was offset by early decreases in feeder poking, rearing, and investigating (Figure 5). A terminal rise in feeder poking was compensated for by declines in rearing and locomoting. Rearing increased in the middle of the interval (Figure 5).

The results support the conclusion that both groups evince the effects of schedule control in the enhancement of feeder poking and the compensatory decrease in other behaviors in the terminal phase of the interval. The pelletfed animals also show schedule-induction effects in the rise in licking early in the interval. By contrast, powderfed rats failed to exhibit any increase in any behavior early in the interval. It is concluded that the evidence on excessivenes and on the time course of behaviors suggests that the powder rats failed to develop any scheduleinduced effects over the 10 sessions of the acquisition condition. Licking by the powder rats not only did not increase, it remained a facultative behavior. Their high incidence of feeder poking early in the interval at asymptote was not schedule induced, but was normal in the sense that it was present from the first session.

Heightened arousal. If the powder rats were less aroused than the pellet rats, then compared with the pellet rats, the powder rats should have lower frequencies of locomotion and rearing in the massed-food condition. If food preferences reflect the arousal-inducing capability of food, then pellets and granular food should be preferred to powder; however, there should be no clear preference for pellets over granular food.

A one-way ANOVA was applied to the bout frequency per trial and the bout duration per trial for each behavior in the comparison of the two groups in the first massedfood condition. Rats with current histories of scheduled pellet treatment exceeded the bout frequency of those on powder for licking, rearing, locomoting, and investigating (Table 4). There were no differences between the two groups on bout duration of any behavior (no data presented).

The first $15 \mathrm{~min}$ of the ingestion sessions were divided into six bins of $150 \mathrm{sec}$ each for analysis of which food 


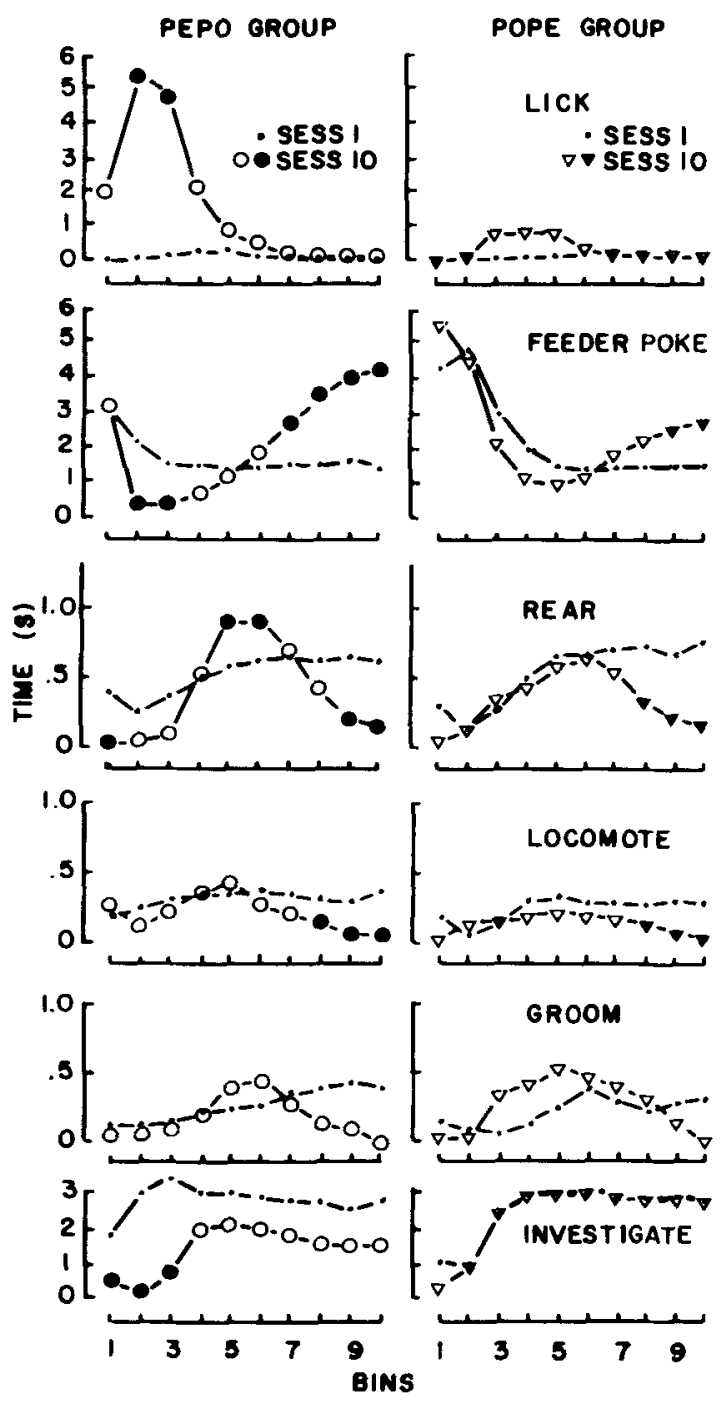

Figure 5. Mean time (in seconds per 6-sec bin) that rats spent licking, feeder poking, rearing, locomoting, grooming, and investigating in the 60-sec interfood delivery interval, for Session 1 (dots) and Session 10 (open symbols) in the acquisition condition. The left column shows time for Group PEPO (circles; $n=8$ ) receiving pellets, and the right column shows time for Group POPE (triangles; $n=8$ ) receiving powder. Standard errors are less than $15 \%$ of the means. Shaded data points $=p<.05$, Newman-Keuls comparison of session means within intervals and within groups.

was eaten first. A groups $\times$ food types $\times$ bins ANOVA indicated that there were no differences between groups with regard to precedence. Consequently, the group data were pooled and ANOVAs of food types $x$ bins were performed on precedence measured as time per bin allocated to eating each type of food, and on precedence measured as ingestive mass of food eaten per bin. NewmanKeuls tests showed that temporal precedence, defined as a significant effect in time allocation in Bin 1, indicated that granular food was most preferred, pellets next, and powder least (Table 5). Ingestive mass precedence, defined as a significant Bin 1 effect, showed that pellets were most preferred, then granular food, then powdered food
(Table 5). Thus, the powdered food was least preferred with respect both to pellets and to granular food, whereas there was no consistent preference between pellets and granular food. The effects seen in Bins 2 and 3 were the result of the bulk of the preferred food having already been consumed.

Thus, several lines of evidence suggest that the rats fed powder on a schedule were not as aroused as those fed pellets. The powder rats exhibited a lower incidence of locomotion and rearing behaviors in a situation free of the direct influence of the schedule. Such behaviors increase under high arousal induced by a stimulant (Fray et al., 1980). Moreover, the differences were caused by increases in bout frequency, not bout duration, an effect previously noted in rats aroused by novelty (Beck \& Chow, 1984) and by amphetamine injection (Beck, Chow, \& Cooper, 1986; Norton, 1973). The increased rearing in the middle of the interval seen in pellet rats in the final session relative to the first session of the acquisition condition, also may be attributable to the heightening of arousal (Figure 5). The measures of precedence indicated that the animals preferred pellets and granular food, both of which produced polydipsia, over powdered food, which did not. This suggests that some property of pellets and granular food, in interaction with food deprivation and the thin schedule of reinforcement, potentiated arousal.

\section{GENERAL DISCUSSION}

The principal finding of these experiments is that hungry rats become polydipsic when fed pellets on a schedule, but not when fed equivalent amounts of food powder on the same schedule. The effect was replicated in an independent experiment and in a condition in which animals were used as their own controls. It was suggested that the powder-fed rats did not drink excessively because schedule induction did not take place. The evidence for this was that their behavior did not differ from that seen in massed-food and no-food conditions, that the effects of schedule control could account for developmental changes in terminal behaviors, and that they did not exhibit the heightened arousal typical of polydipsic rats.

Table 3

ANOVA $F$ Values for Session $\times$ Bin Interactions of Time (in seconds per 6-sec bin) for Coded Behaviors Comparing the First and Last Sessions of the Acquisition Condition

\begin{tabular}{lcr}
\hline \multicolumn{1}{c}{ Behavior } & $d f$ & $F$ \\
\hline & Pellet Group (PEPO) & \\
Licking & $2.3,32.0$ & $37.81 \dagger$ \\
Feeder Poking & $3.1,42.8$ & $40.40 \dagger$ \\
Rearing & $4.1,57.8$ & $4.88^{*}$ \\
Locomoting & $3.7,52.3$ & $4.62^{*}$ \\
Investigating & $2.6,37.0$ & $7.47 \dagger$ \\
& & \\
& Powder Group (POPE) & \\
Feeder Poking & $3.5,48.4$ & $11.82 \dagger$ \\
Rearing & $4.3,59.8$ & $4.39^{*}$ \\
Locomoting & $4.4,61.3$ & $6.15 \dagger$ \\
\hline
\end{tabular}

${ }^{*} p<.01 .+p<.001$. 
Table 4

Mean \pm Standard Errors of Bout Frequency and $F$ Values for ANOVA of Groups in the First Massed-Food Condition

\begin{tabular}{lrrrr}
\hline & \multicolumn{2}{c}{ Groups } & & \\
\cline { 2 - 4 } \multicolumn{1}{c}{ Behavior } & \multicolumn{1}{c}{ Pellet } & Powder & df & \multicolumn{1}{c}{$\boldsymbol{F}$} \\
\hline Licking & $2.3 \pm 0.2$ & $0.9 \pm 0.1$ & 1,14 & $21.24 \dagger$ \\
Rearing & $16.0 \pm 0.9$ & $9.0 \pm 0.8$ & 1,14 & $6.39^{*}$ \\
Locomoting & $36.0 \pm 2.8$ & $23.8 \pm 2.1$ & 1,14 & $10.97 \dagger$ \\
Investigating & $35.5 \pm 1.3$ & $26.5 \pm 2.7$ & 1,14 & $8.97 \dagger$ \\
\hline${ }^{*} p<.05 . \dagger p<.01$. & & &
\end{tabular}

The data pose dilemmas for several theories of scheduled-pellet-induced polydipsia. Models based on thirst (Stein, 1964), schedule induction (Falk, 1967), or a period of low probability of food delivery (the $S-$ model; Staddon, 1977) would have difficulty accounting for the absence of polydipsia in the hungry rats fed dry food powder on an FT 60 -sec schedule. The hypothesis that excessive drinking occurs because of thwarting or frustration (Thomka \& Rosellini, 1975), or because of an increased motivation to eat (Reid \& Dale, 1983), would not have predicted the absence of polydipsia in the nofood intervals in the omitted-food condition. There were abrupt shifts from polydipsia to no polydipsia when rats were switched from pellets to powder. Abrupt changes back and forth between the states occurred from interval to interval in the omitted-food condition. These effects were too rapid to be accounted for by an associative conditioning process, such as extinction (Pavlov, 1927, p. 53) or conditioned inhibition (Pavlov, 1927, p. 70), as would be assumed to occur in models emphasizing adventitious learning (Clark, 1962) or S- (Staddon, 1977). This result also would not be predicted by a model that assumes temporal conditioning to be operative (Pavlov, 1927, p. 41). In associative conditioning, even of the aversive type, the animal becomes less aroused as its performance approaches asymptote and successful levels of responding (Berger, Starzec, \& Mason, 1981). By contrast, polydipsic rats at asymptote are highly aroused. Rats fed powder and pellets on schedule exhibited terminal behaviors in the food delivery interval, indicating that they were responsive to the time course of the probability of food delivery. Given this, the $\mathbf{S}-$ model of polydipsia (Staddon, 1977) would have difficulty explaining the reciprocal relation between feeder poking and drinking. Although the rats took longer to consume powdered food than pellets, they still had a lengthy period of low probability of food delivery to allocate to drinking.

The design of the conditions in the present study was based on methodological and empirical issues. In the introduction, we did not present a preferred model of polydipsia because no theoretical model guided the research. A post hoc review, however, supported the hypothesis that schedule induction gradually developed in the pelletfed rats by sensitization.

Sensitization is a nonassociative form of learning in which the response elicited by a stimulus increases gradually with repeated presentations of the stimulus. A prerequisite or corequisite of the stimulus series is that the animal be aroused, for example, through food deprivation or inescapable aversive stimulation (Petrinovich, 1984). Once the animal is sensitized, the ease of eliciting the exaggerated response persists. Failure to present the stimulus results in abrupt absence of expression of the response. In the case of scheduled-pellet-induced polydipsia, the drinking of water is sensitized by the repeated pellet presentations in an animal aroused by food deprivation, the thin schedule of reinforcement, and consumption of a preferred food. Heightened arousal would be expected to be sustained in the animal even after asymptote is reached (Petrinovich \& Patterson, 1980). Sensitization led to excessive drinking in the pellet rats, but was prevented in powder rats by the oral behavior normally elicited by powder ingestion. Apparently, the granular food also did not elicit enough oral behavior to prevent sensitization. The antipolydipsic effects of large amounts

Table 5

Mean Precedence Scores (per 150-sec Bin) of Ingestion Conditions with ANOVA $F$ Values for Food Type $\times$ Bin Interactions

\begin{tabular}{|c|c|c|c|c|c|c|c|c|}
\hline \multirow[b]{2}{*}{ Measure* } & \multirow[b]{2}{*}{ Food } & \multicolumn{5}{|c|}{ Bins } & \multirow[b]{2}{*}{$d f$} & \multirow[b]{2}{*}{$\boldsymbol{F}$} \\
\hline & & 1 & 2 & 3 & 4 & 5 & & \\
\hline \multicolumn{9}{|c|}{ First Ingestion Condition } \\
\hline Mass & $\begin{array}{l}\text { Pellet } \\
\text { Powder } \\
\text { Pellet } \\
\text { Powder }\end{array}$ & $\begin{array}{c}57.8 \dagger \\
35.8 \\
1014.8 \dagger \\
190.4\end{array}$ & $\begin{array}{c}7.6 \dagger \\
91.1 \\
101.8 \dagger \\
499.8\end{array}$ & $\begin{array}{c}0.5 \dagger \\
68.1 \\
8.4 \dagger \\
363.3\end{array}$ & $\begin{array}{r}0.0 \\
15.4 \\
0.0 \\
66.5\end{array}$ & $\begin{array}{l}0.0 \\
1.1 \\
0.0 \\
5.0\end{array}$ & $1.5,45.0$ & $35.11 \S$ \\
\hline \multicolumn{9}{|c|}{ Second Ingestion Condition } \\
\hline Time & $\begin{array}{l}\text { Pellet } \\
\text { Granule }\end{array}$ & $\begin{array}{l}51.5 \dagger \\
75.5\end{array}$ & $\begin{array}{l}13.4 \dagger \\
44.9\end{array}$ & $\begin{array}{l}0.0 \\
0.9\end{array}$ & $\begin{array}{l}0.0 \\
0.0\end{array}$ & $\begin{array}{l}0.0 \\
0.0\end{array}$ & $1.2,37.3$ & $8.99 \ddagger$ \\
\hline Mass & $\begin{array}{l}\text { Pellet } \\
\text { Granule }\end{array}$ & $\begin{array}{l}918.7 \dagger \\
702.6\end{array}$ & $\begin{array}{l}206.3 \dagger \\
415.6\end{array}$ & $\begin{array}{l}0.0 \\
6.8\end{array}$ & $\begin{array}{l}0.0 \\
0.0\end{array}$ & $\begin{array}{l}0.0 \\
0.0\end{array}$ & $1.0,30.40$ & $8.42 \S$ \\
\hline Time & $\begin{array}{l}\text { Powder } \\
\text { Granule }\end{array}$ & $\begin{array}{l}50.8 \dagger \\
78.2\end{array}$ & $\begin{array}{c}113.8 \dagger \\
15.2\end{array}$ & $\begin{array}{c}58.4 \dagger \\
2.2\end{array}$ & $\begin{array}{l}5.3 \\
0.0\end{array}$ & $\begin{array}{l}0.0 \\
0.0\end{array}$ & $1.9,57.1$ & 23.188 \\
\hline Mass & $\begin{array}{l}\text { Powder } \\
\text { Granule }\end{array}$ & $\begin{array}{l}250.4 \dagger \\
920.1\end{array}$ & $\begin{array}{l}560.8 \dagger \\
178.7\end{array}$ & $\begin{array}{c}287.6 \dagger \\
26.2\end{array}$ & $\begin{array}{r}26.2 \\
0.0\end{array}$ & $\begin{array}{l}0.0 \\
0.0\end{array}$ & $1.4,42.8$ & 38.528 \\
\hline
\end{tabular}

* Standard Errors are less than $10 \%$ of mears. Time = time food eaten in seconds per bin. Mass = mass of food ingested in milligrams per bin. $t p<.05$. $\ddagger p<.01$. $\$ p<.001$. 
of food portray the same reciprocal relation between head in the feeder and drinking (Reid \& Dale, 1983), and thus are accounted for by the same process. Massed-food presentations of pellets do not support polydipsia, even in animals that are currently exhibiting scheduledpellet-induced polydipsia, for the same reason. Failure to present the eliciting stimulus results in the immediate absence of the expression of the sensitized response (Petrinovich, 1984). Thus, no-food sessions, and even nofood intervals, result in no polydipsic response. The effect of the absence of an elicitor is also operative in the switching of polydipsic rats from pellets to powder. Finally, the absence of polydipsia in the first few sessions of scheduled-pellet-induced polydipsia training in naive animals is due to the fact that the sensitization takes some time to develop (Petrinovich, 1984).

\section{REFERENCES}

Beck, С. Н. M., CHow, H. L. (1984). Solitary and social behavior of male rats in the open-field. Physiology \& Behavior, 32, 941-944.

Beck, C. H. M., Chow, H. L., \& CoOPER, S. J. (1986). Initial environment influences amphetamine-induced stereotypy: Subsequently environment change has little effect. Behavioral \& Neural Biology, 46, 383-397.

Berger, D. F., Starzec, J. J., \& Mason, E. B. (1981). The relationship between plasma corticosterone levels and leverpress avoidance vs. escape behaviors in rats. Physiological Psychology, 9, 81-86.

Clark, F. C. (1962). Some observations on the adventitious reinforcement of drinking under food reinforcement. Journal of the Experimental Analysis of Behavior, 5, 61-63.

COOK, P., \&INGER, G. (1976). Effects of stimulus displacement on adjunctive behavior. Physiology \& Behavior, 16, 79-82.

Cook, P., Wallace, M., \&inger, G. (1983). A reinterpretation of schedule-induced behaviors based on a systematic analysis of behavior. Neuroscience \& Biobehavioral Reviews, 7, 97-104.

CoOper, S. J., \& Francis, R. L. (1979). Effects of acute or chronic administration of chlordiazepoxide on feeding parameters using two food textures in the rat. Jourmal of Pharmacy \& Pharmacology, 31, 743-746.

FALK, J. L. (1967). Control of schedule-induced polydipsia: Type, size, and spacing of meals. Journal of the Experimental Analysis of Behavior, 10, 199-206.

FALK, J. L. (1971). The nature and determinants of adjunctive behavior. Physiology \& Behavior, 5, 325-335.

File, S. E., \& PEET, L. A. (1980). The sensitivity of the rat corticosterone response to environmental manipulations and to chronic chlordiazepoxide treatment. Physiology \& Behavior, 25, 753-758.

FLORY, R. K. (1971). The control of schedule-induced polydipsia: Frequency and magnitude of reinforcement. Learning \& Motivation, 2 , 215-227.

FLORY, R. K., O'BoYLE, M. K. (1976). The effect of limited water availability on schedule-induced polydipsia. Physiology \& Behavior, 8, 147-149.

Fray, P. J., Sahakian, B. J., Robeins, T. W., Koob, G. F., \& IVerSEN, S. D. (1980). An observational method for quantifying the behavioral effects of dopamine agonists: Contrasting effects of damphetamine and apomorphine. Psychopharmacology, 69, 253-259.

Greenhouse, S. W., GeISSER, S. (1959). On methods in the analysis of profile data. Psychometrika, 24, 95-112.

LiPSETT, L. P., \& KAYE, H. (1965). Change in neonatal response to optimizing and non-optimizing sucking stimulation. Psychonomic Science, 2, 221-222.
Lorenzini, C. A., Bucherelu, C., \& Giachetti, A. (1986). Some factors influencing conditioned and spontaneous behavior of rats in the light-dark box test. Physiology \& Behavior, 36, 97-101.

Mittleman, G., Jones, G. H., Robins, T. W. (in press). The relationship between schedule-induced polydipsia and pituitary-adrenal activity: Pharmacological and behavioral manipulations. Behavioral Brain Research.

Mittleman, G., \& Valenstein, E. S. (1985). Individual differences in nonregulatory ingestive behavior and catecholamine systems. Brain Research, 348, 112-117.

Naim, M., Brand, J. G., Christensen, I. M., Kare, M. R., \& Van Buren, S. (1986). Preference of rats for food flavors and texture in nutritionally controlled semi-purified diets. Physiology \& Behavior, 37, 15-21.

NorTon, S. (1973). Amphetamine as a model for hyperactivity in the rat. Physiology \& Behavior, 11, 181-186.

Pavlov, I. P. (1927). Conditioned reflexes. Oxford: Oxford University Press.

Petrinovich, L. (1984). A two-factor dual-process theory of habituation and sensitization. In H. V. S. Peeke \& L. Petrinovich (Eds.), Habituation, sensitization, and behavior (pp. 17-55). Orlando, FL: Academic Press.

Petrinovich, L., \& Patterson, T. L. (1980). Field studies of habituation: III. Playback contingent on the response of the white-crowned sparrow. Animal Behavior, 28, 742-751.

ReID, A. K., DALe, R. H. I. (1983). Dynamic effects of food magnitude on interim-terminal interaction. Joumal of the Experimental Analysis of Behavior, 39, 135-148.

ROPER, T. J. (1981). What is meant by the term "schedule-induced," and how general is schedule induction? Animal Learning \& Behavior, 9, 433-440.

Roper, T. J., Edwards, L., \& Crossland, G. (1983). Factors affecting schedule-induced wood-chewing in rats: Percentage and rate of reinforcement, and operant requirement. Animal Leaming \& Behavior, 11, 35-43.

Roseluin, R. A., Burdette, D. R. (1980). Meal size and intermeal interval both regulate schedule-induced water intake in rats. Animal Learning \& Behavior, 8, 647-652.

SANGer, D. J., Blackman, D. E. (1975). The effects of chlordiazepoxide on the development of adjunctive drinking in rats. Quarterly Journal of Experimental Psychology, 27, 499-505.

SheAron, T. O., \& ALLEN, J. D. (1984). Facilitation of schedule-induced behavior. Bulletin of the Psychonomic Society, 22, 467-468.

STAdDon, J. E. R. (1977). Schedule-induced behavior. In W. K. Honig \& J. E. R. Staddon (Eds.), Handbook of operant behavior (pp. 125152). Englewood Cliffs, NJ: Prentice-Hall.

STEIN, L. (1964). Excessive drinking in the rat: Superstition or thirst? Journal of Comparative \& Physiological Psychology, 58, 237-242.

Tazi, A., Dantzer, R., Mormede, P., \& Le Moal, M. (1986). Pituitary-adrenal correlates of schedule-induced polydipsia and wheel running in rats. Behavioural Brain Research, 19, 249-256.

THомkA, M. L., \& RoseluINI, R. A. (1975). Frustration and the production of schedule-induced polydipsia. Animal Learning \& Behavior, 3, 380-384.

ULRICH, R. E. , \& AZRIN, N. H. (1962). Reflexive fighting in response to aversive stimulation. Journal of the Experimental Analysis of Behavior, 5, 511-520.

WETHERINGTON, C. L. (1982). Is adjunctive behavior a third class of behavior? Neuroscience \& Biobehavioral Reviews, 6, 329-350.

Wetherington, C. L., \& RiLeY, A. L. (1986). Diminution of scheduleinduced polydipsia after a long rest period. Physiology \& Behavior, 37, 375-378.

(Manuscript received September 9, 1987; revision accepted for publication June 27,1988 .) 